\title{
An Intelligent Irrigation System for Rural Agriculture
}

\section{Jerry John Kponyo, Kwasi Adu-Boahen Opare, Ahmed Abdul-Rahman, Justice Owusu Agyemang}

College of Engineering, Kwame Nkrumah University of Science and Technology, Kumasi, Ghana

\section{Email address:}

jjkponyo.soe@knust.edu.gh (J. J. Kponyo), opareaduboahen@yahoo.co.uk (K. Adu-Boahen O.),

enuznam.soe@knust.edu.gh (A.Abdul-Rahman),justiceowusuagyemang@gmail.com (J. O. Agyemang)

\section{To cite this article:}

Jerry John Kponyo, Kwasi Adu-Boahen Opare, Ahmed Abdul-Rahman, Justice Owusu Agyemang. An Intelligent Irrigation System for Rural Agriculture. International Journal of Applied Agricultural Sciences. Vol. 5, No. 3, 2019, pp. 75-81. doi: 10.11648/j.ijaas.20190503.13

Received: January 11, 2019; Accepted: March 5, 2019; Published: July 13, 2019

\begin{abstract}
The agricultural sector significantly contributes to the economic growth of every country. This sector faces challenges with respect to producing the right quantity and quality of food. Most traditional methods used in growing crops are inadequate to ensuring food security. This challenge can be addressed by applying Information and Communication Technology (I.C.T.) in the agricultural sector. In the cultivation of crops, the use of proper irrigation method is essential in enhancing the growth and yield of crops. This research focuses on the application of information technology to provide the required amount of water needed by crops for growth. With the emergence of Internet of Things (IoT) which involves the interconnection of electronic devices to the Internet and the acquisition of data from these devices through the use sensors, an IoT based Intelligent Irrigation System was built. The Intelligent Irrigation System consisted of a transmitter and a receiver circuit (which is connected to a water pump via an actuator). The transmitter circuit was responsible for reading the moisture content of the soil and transmitting it wirelessly to the receiver. The receiver then made decisions on whether to trigger the pump on or off depending on the received soil moisture data. The Intelligent Irrigation System was piloted on a carrot farm. A total of 16 beds were constructed for the study. It was divided into 2 different blocks. The first block comprised of 8 beds which were manually irrigated and the second block was made up of 8 beds which were irrigated by means of machine-tomachine (M2M) communication. For pre-harvest, the performance indicators used were the height of the plants and the number of leaves per plant. The weight, length and diameter of the carrot plants were used as performance indicators for postharvest. It was realized that the crops that were watered via M2M communication showed better growth performances as compared to those that were watered manually.
\end{abstract}

Keywords: GSM, RF, Microprocessor, IoT

\section{Introduction}

The world's population is predicted to be about 9 billion in the year 2050. The rapid population growth together with the rise of living standards requires effective measures that will increase food production hence ensuring food security.

The agricultural sector is currently facing challenges with respect to producing the right quantity and quality of food to deal with issues of malnutrition. The agricultural sector affects the economic growth of every country through the increase of food supply and fiber for domestic consumption. The sector releases excess labor to the industrial sector, increases domestic saving, generates foreign exchange through exports and also provides cheaper non-tradable agricultural products thus lowering the wage-goods price [1].
With the current evolution of technology, the application of Information Technology (I.T.) in the agricultural sector has become necessary. Various techniques have been adopted by many researches aimed at improving the yields of the agricultural sector through the adoption of Smart Irrigation technology.

This paper presents results on how intelligent irrigation proves itself to be efficient in enhancing the yield of carrots in rural agriculture. The rest of this paper is organized as follows: Section 2 reviews related literature. Section 3 presents the methodology. Section 4 presents the results of the study. Section 5 is the conclusion and recommendation.

\section{Review of Related Works}

The evolution of smart technologies has led most 
researchers and engineers to adopt this evolving technology into the agricultural sector. The smart irrigation system is aimed at making sure crops grown on farms have the desired amount of water needed for their growth.

Siyu et al. [2] developed a smart watering irrigation system where they connected a microprocessor (an Arduino) to a soil moisture sensor that recorded moisture in the soil. They connected an actuator to the microprocessor which was also connected to a pump. The actuator was triggered if the soil moisture fell below the desired threshold. The data was then sent to a database server and visualized on a web interface.

Michael et al. [3] developed a smart irrigation system consisting of a timer, a Soil Moisture Sensor (SMS) and SMS controller. In their setup, the irrigation timer is connected to a solenoid valve through a hot and a common wire. The common wire is spliced with the SMS system (a controller that acts as a switch, and a sensor buried in the root zone that estimates the soil water content). The SMS takes a reading of the amount of water in the soil and the SMS controller uses that information to open or close the switch. If the soil water content is below the threshold established by the user, the controller will close the switch, allowing power from the timer to reach the irrigation valve and trigger irrigation.

Harishankar et al. [4] developed an automated irrigation system that uses solar as its source of power. Their irrigation system was used to drive a pump which further pumps water from a bore-hole into a tank. The outlet valve of the tank was automatically regulated through the use of a micro-controller and a moisture sensor.

iCentral Internet Irrigation System allows a centralized computer system the ability to automatically program and control all aspects of field irrigation controllers, regardless of their location. When combined with water sensing instrumentation, the central control system can determine the daily Evapotranspiration (ET) rate, and adjust irrigation schedules appropriately by downloading new irrigation programs to the field controllers (called satellites) every day [5].

Archana et al. [7] proposed a paper in which the humidity and soil moisture sensors are placed in the root zone of the plant. The microcontroller coordinates the way water is supplied to the roots based on the readings from the sensors.

Sonali et al. [8] proposed a system in which soil parameters such as $\mathrm{pH}$, humidity, moisture and temperature are measured for getting high yield from the soil. Their system was fully automated which turned the motor pump on/off as per the level of the moisture in the soil.

R. Subalakshmi [9] proposed a system that makes use of a microcontroller and GSM. Based on the sensed values from soil moisture, temperature and humidity sensors, the GSM sends message to the farmer when these parameters exceed the threshold value set in the program.

Karan Kasara et al. [10] proposed an automated irrigation system where the humidity and temperature sensors are used to sense soil conditions and based on that, a microcontroller controls the water flow.

C. H. Chavan et al. [11] proposed a smart wireless sensor network for monitoring environmental parameters using ZigBee. These nodes send data wirelessly to a central server, which collects data, stores it and analyzes the data.

Yunseop Kim [12] proposed a paper in which the field conditions were site-specifically monitored by six on-field sensor stations.

The above reviewed works lack the ability to provide realtime analytics of the field conditions, remote override and flexibility. This research provides manual override via a web and mobile applications; hence more flexibility. Besides it provides real-time analytics of the field conditions.

\section{Methodology}

With the evolution of Internet of Things (IoT) which deals with the interconnection of electronic devices and the acquisition of data from these devices through the use of sensors, the Intelligent Irrigation System was built to include this emerging technology.

\subsection{System Design}

The Intelligent Irrigation System consisted of a transmitter circuit and a receiver circuit. Data gathered by the transmitter circuit was sent wirelessly to the receiver circuit. The operating radio frequency for data transmission and reception was $433 \mathrm{MHz}$ [13].

The transmitter circuit consisted of an RF $433 \mathrm{MHz}$ transmitter, an Arduino microcontroller [14] and a SparkFun soil moisture sensor [15] as shown in Figure 1. The soil moisture sensor was responsible for reading the moisture level in the soil. The processing was done by the microprocessor and the data was transmitted to the receiver.

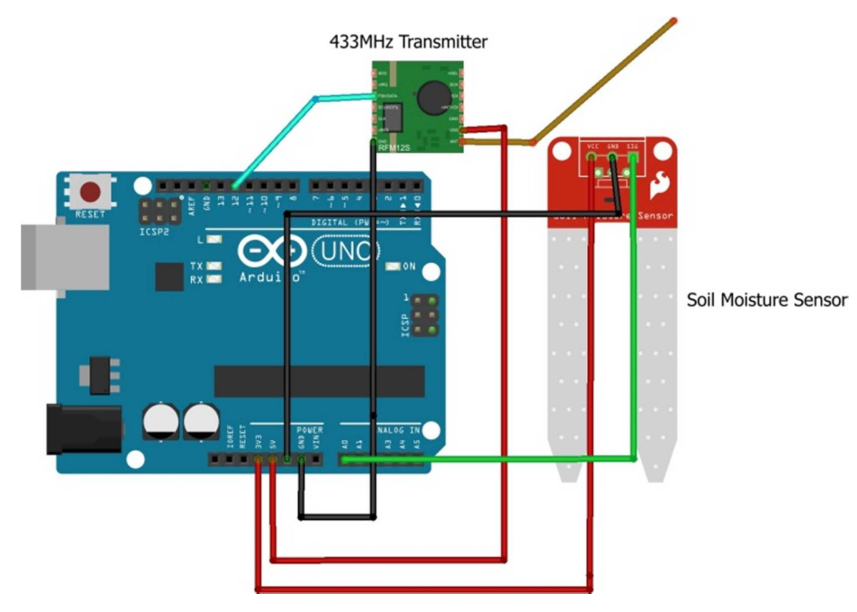

Figure 1. Transmitter Circuit [6].

The receiver circuit consisted of an RF $433 \mathrm{MHz}$ receiver, an Arduino microcontroller, GSM shield and a relay ( shown in Figure 2). The GSM shield acted as a modem for transmitting the received data to an online database server. The relay was used to trigger the pump either on or off depending on the reading received from the transmitter. 


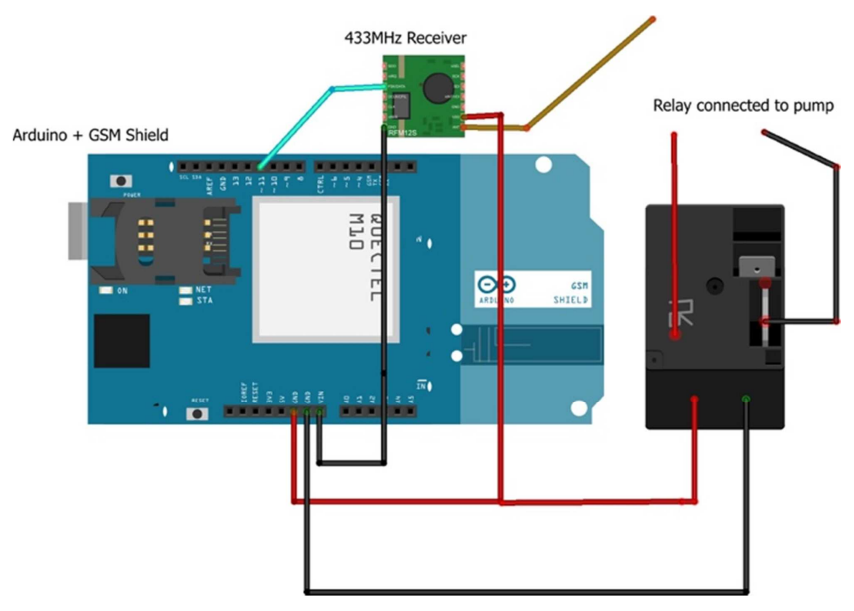

Figure 2. Receiver Circuit [6].

\subsection{Mode of Operation}

The moisture sensor connected to the receiver circuit, recorded the moisture level in the soil. The data was then transmitted wirelessly through the $433 \mathrm{MHz}$ antenna after processing by the micro-controller unit as illustrated by Figures 3 and 4 .

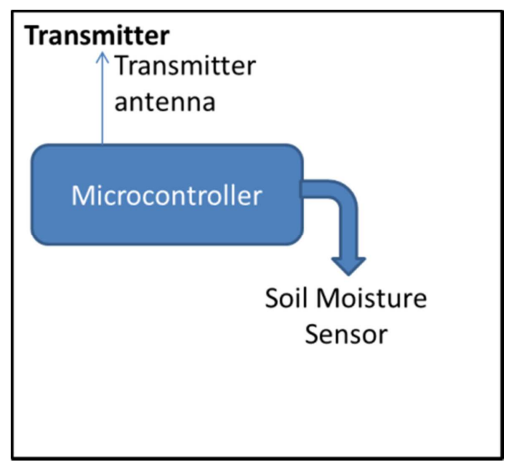

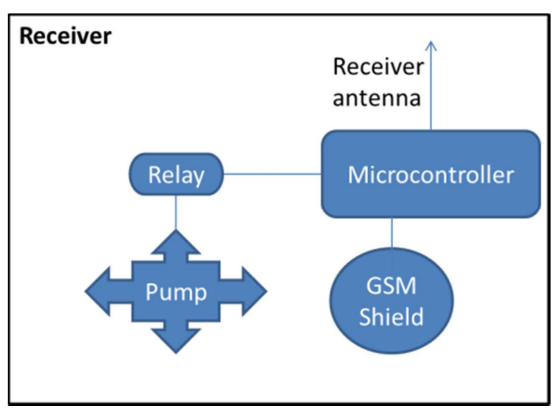

Figure 4. Data Reception and Decision Making.

The receiver circuit receives the data sent from the transmitter circuit through the antenna. The microprocessor performs an operation on the received data to check whether it falls above or below the threshold. If the received value falls below the threshold, it triggers the relay which in turn triggers the pump. The GSM shield relays the data to an online server. It records the time at which device was triggered to pump water and also the time at which the pump was triggered to stop pumping water.

\subsection{End-User Application Interface}

The end-user application consisted of a web and mobile interface that enabled the user to view the various tasks that goes on day-to-day. The web application was developed using HyperText Preprocessor (PHP) as the server side language, HyperText Markup Language (HTML) for the markup and MySQL as the database storage. The end-user application interface was developed to help monitor activities on the farm are shown in Figures 5 to 8 .

\subsubsection{Web Interface}

The web interface consisted of a login page, a dashboard and a data logging page.

Figure 3. Data Transmission.

\section{Smart|rrigation}

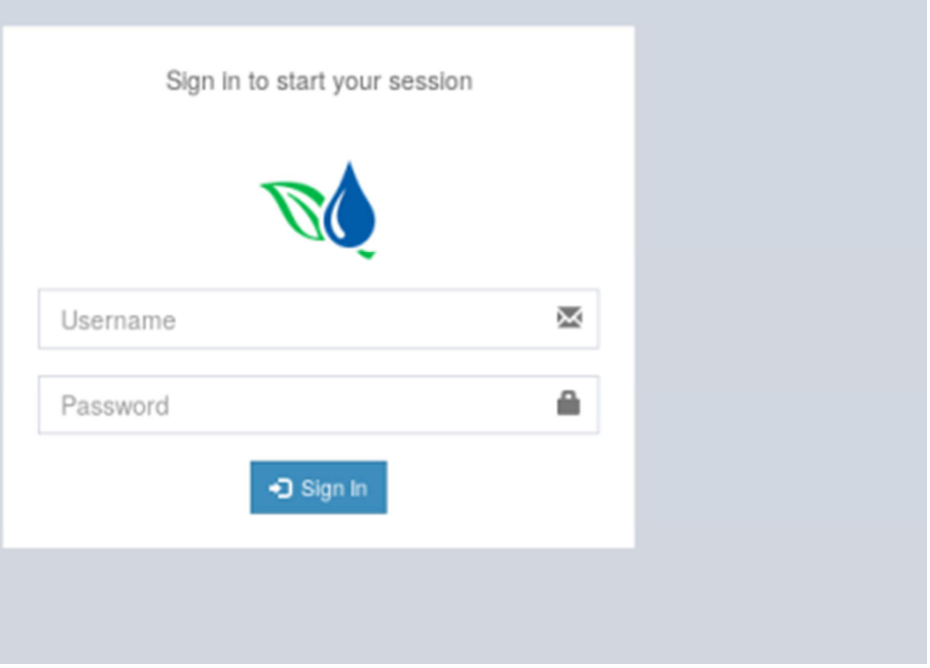

Figure 5. Log in page of Web Interface. 


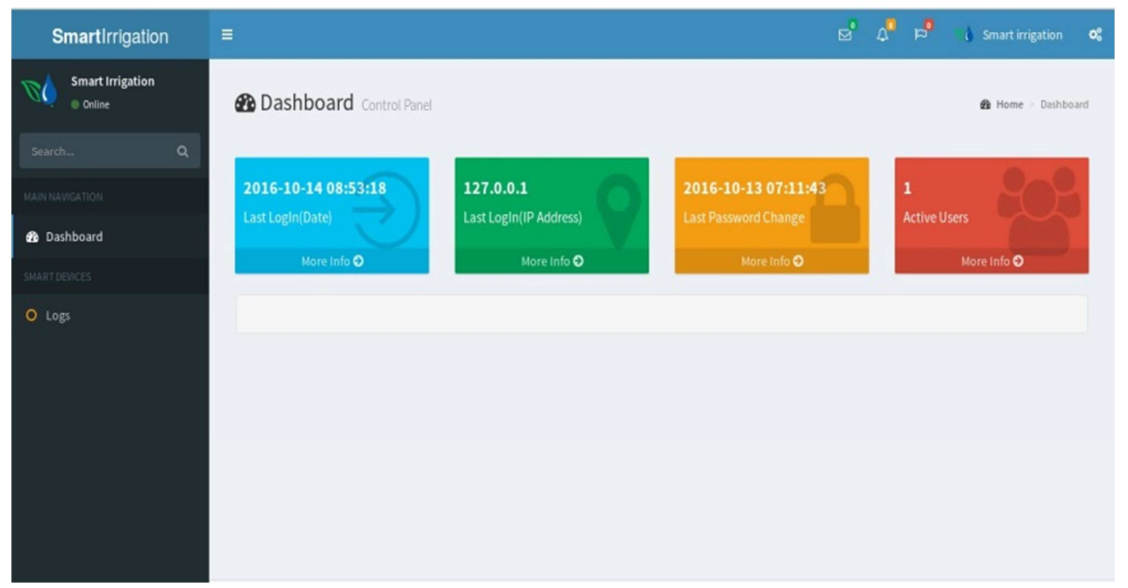

Figure 6. Dashboard of Web Interface.

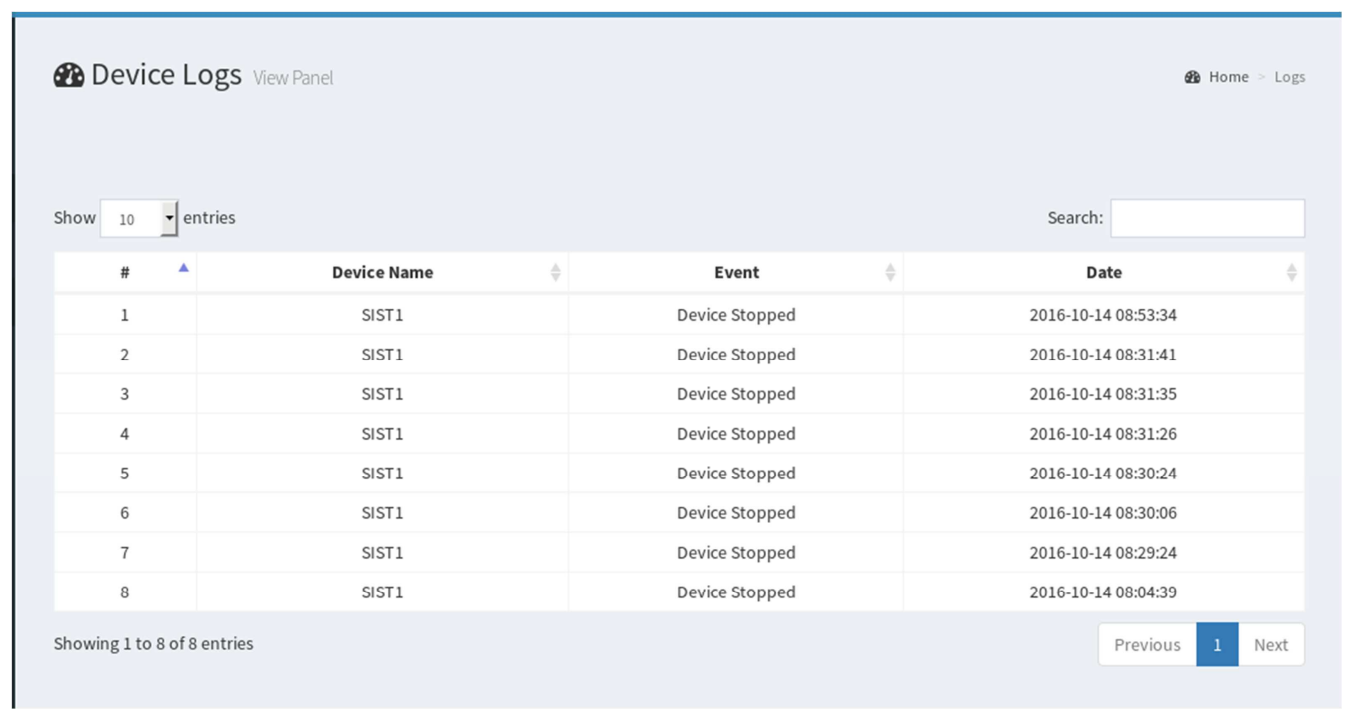

Figure 7. Web Application's Data Logging Page.

\subsubsection{Mobile Application Interface}

The mobile application for the Intelligent Irrigation System was designed only for the android mobile platform. The application consisted of a login page, a data logging page, a dashboard and a notification page.

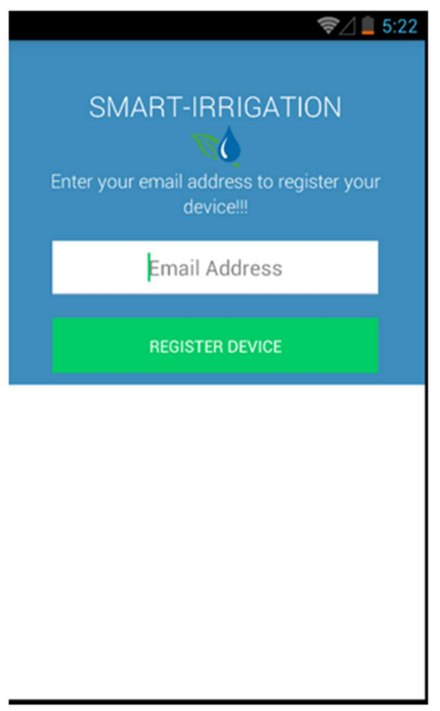

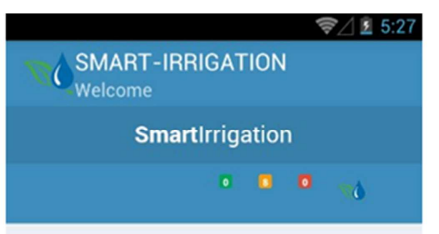
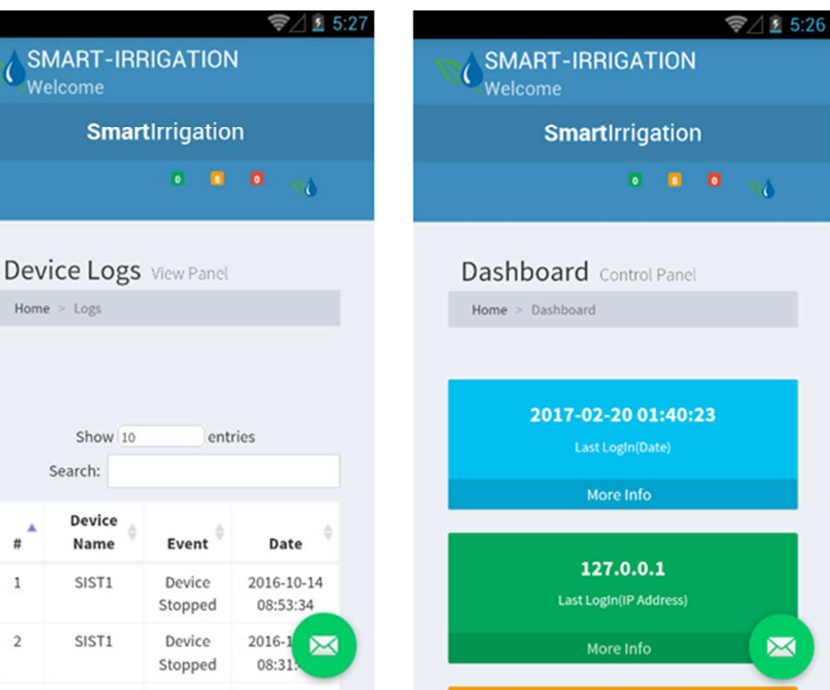

Dashboard control Pancl

Home $\times$ Dashboard
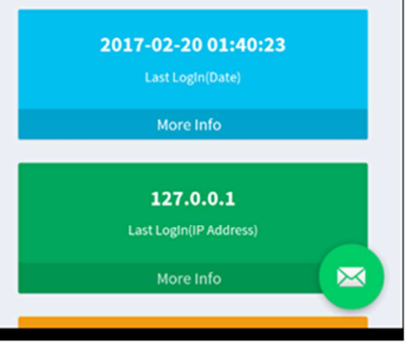

Figure 8. Mobile Application Interface. 


\subsection{Application of Intelligent Irrigation System}

The Intelligent Irrigation System was applied to the growth of carrots. A total of 16 beds were constructed for the study. It was divided into 2 different blocks. The first block comprised of 8 beds which were manually irrigated and the second block also comprised of 8 beds which were irrigated by means of machine-to-machine communication.

For the data collection, 20 individual carrot plants from different rows in each block were randomly selected. For the manual irrigation, 4 watering cans of 14 litters were supplied to each bed daily.

Activities

Table 1 shows the activities which were performed on the farm.

Table 1. Activities and Timelines.

\begin{tabular}{ll}
\hline ACTIVITY & DATE \\
\hline Sowing & 1st November, 2016 \\
Germination & 11th November, 2016 \\
First tinning out and weed control & 21st November, 2016 \\
Organic manure application & 22nd December, 2016 \\
Second weed control & 9th January, 2017 \\
\hline
\end{tabular}

\section{Results and Discussion}

\subsection{Data Collection}

\subsubsection{Pre-Harvest}

For pre-harvest, the following parameters were considered:

1. Plant height.

2. Number of leaves per plant (data gathered at 40 and 50 days after seeds were sowed).

\subsubsection{Post-Harvest}

For post-harvest, the following parameters were considered:

1. Fresh weight of the leaves per plant.

2. Length and diameter of selected harvest carrot.

3. Weight of the root per plant.

4. Branching percentage.

5. Cracking percentage.

\subsubsection{Plant Height}

Plant heights were measured in centimeters (CM) at 40 , and 50 days from the point of attachment of the leaves to the root (ground level) up to the tip of the longest leaf.

\subsubsection{Number of Leaves Per Plant}

Numbers of leaves per plant were counted at 40 and 50 days. All the leaves of each plant were recorded. Only the smallest and young leaves at the time of the plant growth were excluded from the counting.

\subsection{Data Analysis}

The data gathered was in respect to the plant height and the number of leaves on each carrot plant. 20 carrot plants were selected at random in the data gathering process. Sect A is the data acquired from the first 8 beds that were watered using the Intelligent Irrigation System. Sect B is the data acquired from the remaining 8 beds (the controlled experiment).

\subsubsection{Plant Height}

Figures 9 and 10 show the plant heights recorded at different stages of the plant specifically 40 and 50 days after sowing. The plant height varied significantly due to the different rate of water application at a specific time and quantity of water on both the control and the test beds with the plants on the intelligent irrigation farm outperforming the manually irrigated farm.

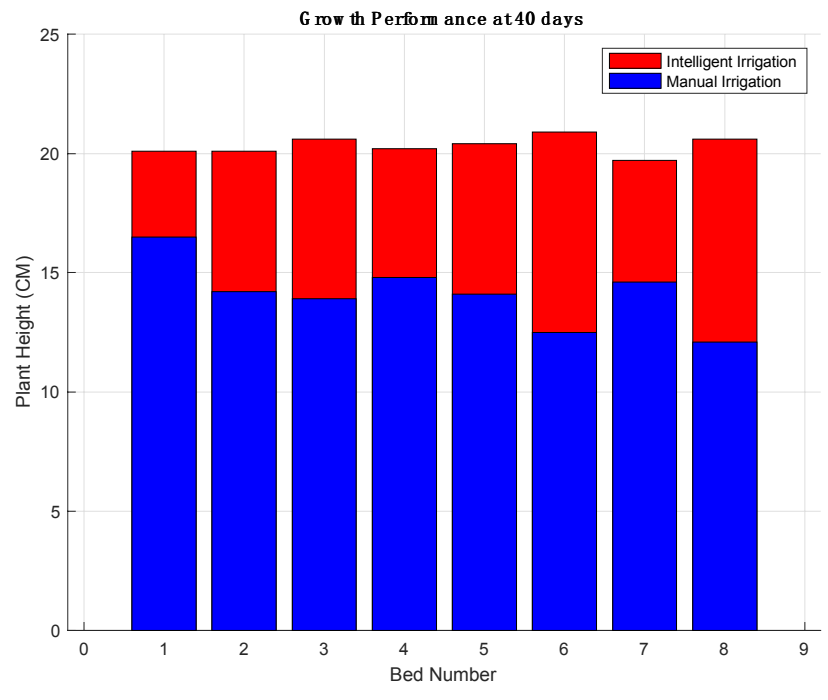

Figure 9. Plant Height - Growth Performance of Carrots at 40 days.

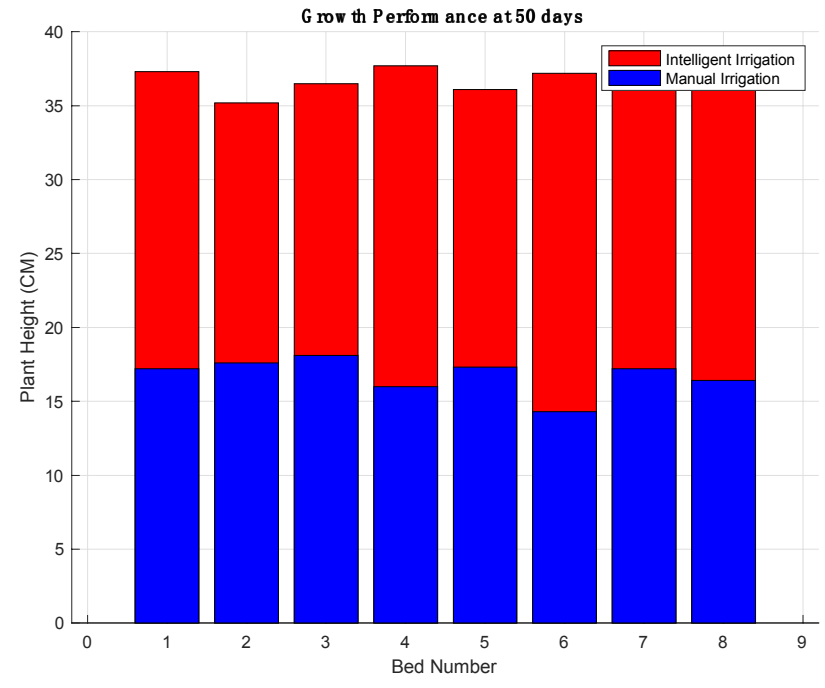

Figure 10. Plant Height - Growth Performance of Carrots at 50 days.

\subsubsection{Number of Leaves}

Figures 11 and 12 show the number of leaves per plant recorded at different stages of the plant, that's 40 and 50 days after sowing. The number of leaves varied significantly due to the different rate and the amount of water application at a 
specific time. Once again it is obvious that the leaves in the case of the intelligently irrigated farm are better than those of the manually irrigated.

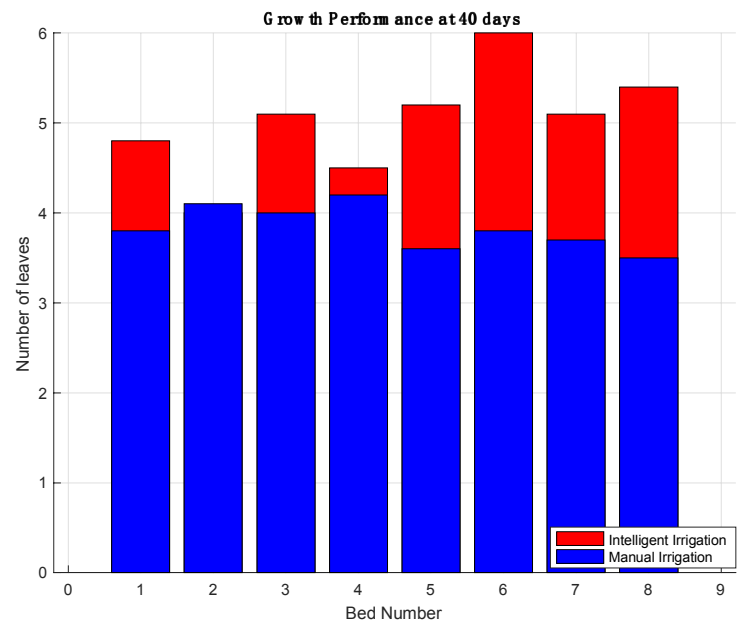

Figure 11. Number of leaves - Growth Performance of Carrots at 40 days.

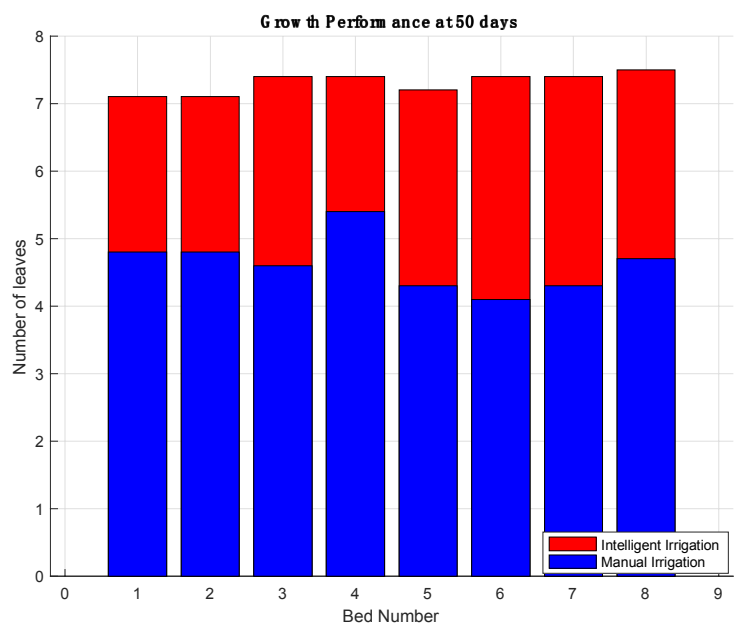

Figure 12. Number of leaves - Growth Performance of Carrots at 50 days.

\subsubsection{Weight of Carrots}

Figure 13 shows the weight (in grams) of 80 randomly selected carrots after harvesting.

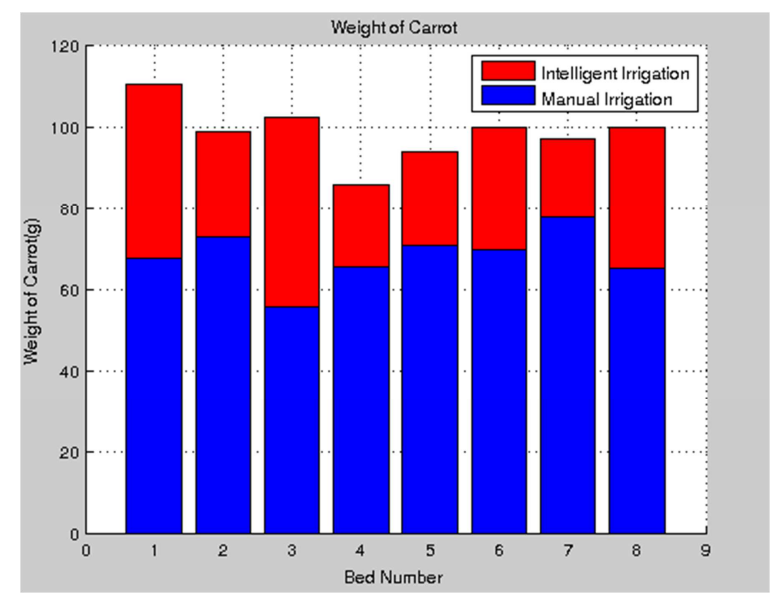

Figure 13. Weight of Carrots (post-harvest).

\subsubsection{Length of Carrots}

Figure 14 shows the length (in centimeters) of 80 randomly selected carrots after harvesting.

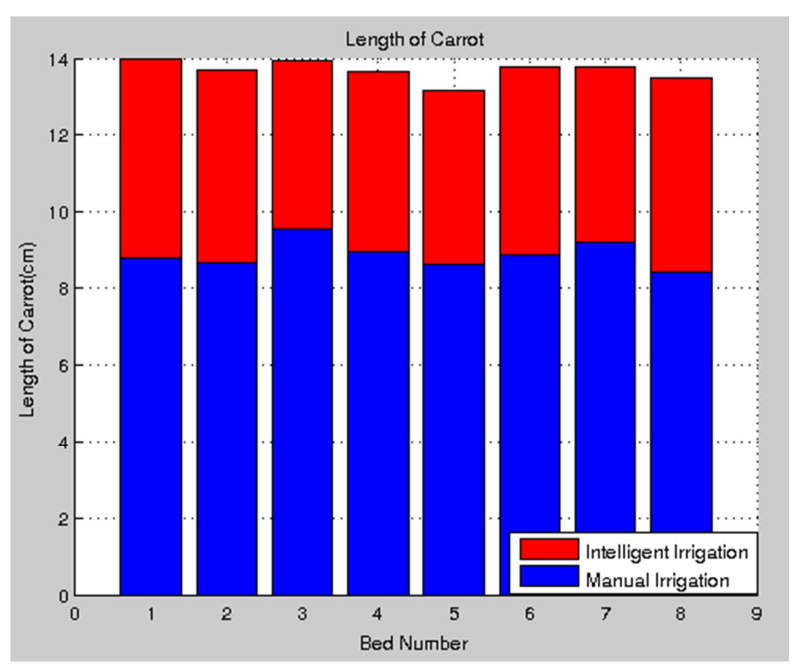

Figure 14. Length of Carrots (post-harvest).

\subsubsection{Diameter of Carrots}

Figure 15 shows the diameter (in centimeters) of 80 randomly selected carrots after harvesting.

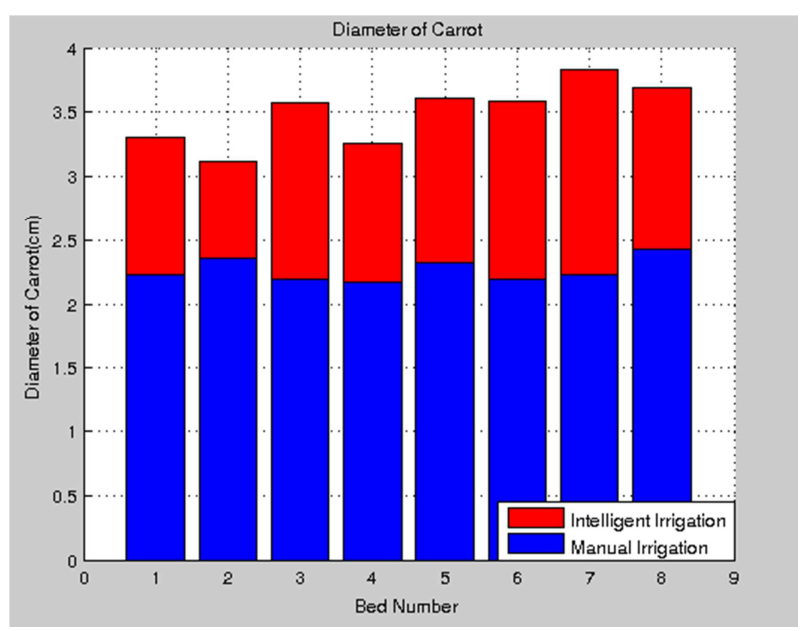

Figure 15. Diameter of carrots (post-harvest).

\subsubsection{Discussion}

From the graphs it can be inferred that the average of 20 randomly selected pants of the machine-to-machine communication showed better growth performance than the manually watered plants. It is observed that there was significant difference in the number of leaves of carrot plants of individual beds which implies that the soil fertility also played an important role in the growth of the carrot plants. The carrot plants that were watered via machine-to-machine communication weighed higher than those that were watered manually in terms of yield weight. Besides, the plants height and the diameter of the plants yield were higher in those plants watered using the intelligent irrigation system than those watered manually. 


\section{Conclusion}

This paper presents an intelligent irrigation system for optimizing water resources for agricultural production. It illustrates how IoT can be applied in providing real-time analytics of field conditions using a wireless data acquisition network. The system proved to be efficient in enhancing the growth and yield of carrots. It is recommended that the system should be implemented on a larger scale to investigate its commercial viability.

\section{References}

[1] Poonyth D., Hassan R., Kristen J. F., Calcaterra M., "Is Agricultural Sector Growth a Precondition for Economic Growth? The Case of South Africa, 2001”, 2001.

[2] Siyu Chen, Nicola Fatras, Haoran Su, "Smart Water Irrigation System",

https://ecal.berkeley.edu/files/ce186/projects/chensiyu_late_461 503463834617 FINAL\%20REPORT FATRAS SU CHEN. pdf, [Accessed Online 20 ${ }^{\text {th }}$ December, 2018].

[3] Michael D. Dukes, Mary Shedd, and Bernard CardenasLailhacar, "Smart Irrigation Controllers: How do Soil Moisture Sensor (SMS) Irrigation Controllers Work?", University of Florida.

[4] S. Harishankar, R. Sathish Kumar, Sudharsan K. P., U. Vignesh, T. Viveknath, "Solar Powered Smart Irrigation System", Department of Electrical and Electronics Engineering, Amrita University, Ettimadai, Coimbatore, India, 2014.

[5] Jonathan A. Goldhill, "Why Smart Water Application Technology Makes Sense", 2004.

[6] Circuit Design using Fritzing, http://fritzing.org/home/, [Accessed Online 14 ${ }^{\text {th }}$ December, 2018].
[7] Archana and Priya, "Design and Implementation of Automatic Plant Watering System", International Journal of Advanced Engineering and Global Technology, vol. 4, Issue 01, January, 2016.

[8] Sonail D. Gainwar and Dinesh V. Rojatkar, "Soil Parameters Monitoring with Automatic Irrigation System", International Journal of Science, Engineering and Technology Research, vol. 4, Issue 11, Nov. 2015.

[9] R. Subalakshmi and Anu Amal, "GSM Based Automated Irrigation using Sensors", Internal Journal of Trend in Research and Development, March, 2016.

[10] Karan Kansara and Visahl Zaweri, "Sensor Based Automated Irrigation System with IoT", International Journal of Computer Science and Information Technologies, vol. 6, 2015.

[11] C. H. Chavan and V. Karnade, "Wireless Monitoring of Soil Moisture, Temperature and Humidity using ZigBee in Agriculture", International Journal of Engineering Trends and Technology, Vol. 11, May 2014.

[12] Yunseop Kim and Robert G. Evans, "Remote Sensing and Control of an Irrigation System using a Distributed Wireless Sensor Network", IEEE Transactions on Instrumentation and Measurement, vol. 56, July 2008.

[13] $433 \mathrm{MHz}$ RF Transceiver and Receiver Module, https://components101.com/sites/default/files/component data sheet $/ 433 \% 20 \mathrm{MHz} \% 20 \mathrm{RF} \% 20$ Receiver$\% 20$ Module_0.pdf, [Accessed Online $14^{\text {th }}$ December, 2018 ].

[14] Arduino Microcontroller, https://www.arduino.cc/en/Main/Products, [Accessed Online $15^{\text {th }}$ December, 2018].

[15] Spark Fun Soil Moisture Sensor, https://www.sparkfun.com/products/13322, [Accessed Online $15^{\text {th }}$ December, 2018]. 